\title{
Does Descartes Have a Principle of Life? \\ Hierarchy and \\ Interdependence in \\ Descartes's Physiology
}

\author{
Barnaby R. Hutchins
}

Ghent University

\begin{abstract}
Descartes repeatedly refers to a "principle of life" and appears to make grand claims for its role in his natural philosophy. These claims bave been taken at face value in the literature. This paper argues that there is no single principle underlying the operation of the Cartesian body. I show that Descartes's account of physiology explains the operation of the living body through multiple interdependent systems, with no one system more fundamental than any other. As such, Cartesian physiology is incompatible with a bierarchical conception of a body whose operations are driven by a single underlying principle.
\end{abstract}

\section{Introduction}

At various points in his work on physiology and medicine, Descartes refers to a "principle of life." The exact term changes-sometimes, it is the "principle of movement and life" (CSM I, p. 108; AT xI, p. 202), sometimes the "principle underlying all [the] functions" of the body (CSM I, p. 331; AT XI, p. 333)—but the message seems consistent: the phenomena of living bodies are the product of a single, underlying principle. That principle is generally taken to be cardiac heat. ${ }^{1}$ The literature has, quite reasonably, taken this message at face value. Thus, Shapiro: "Descartes insists again

Versions of this paper were presented at HOPOS, 3-Societies, the New York City Workshop in Early Modern Philosophy, and CSHPS. My thanks to Boris Demarest, Dennis Des Chene, Daniel Garber, Laura Georgescu, Gideon Manning, Daniel Schneider, Eric Schliesser, Lisa Shapiro, Charles Wolfe, and two anonymous referees for comments and/or discussion.

1. See Bitbol-Hespériès (1990) for an extended argument that Descartes's principle of life is cardiac heat. There is, however, some variation in Descartes's discussion of the principle (e.g., "the souls of animals are nothing but their blood" (to Plempius for Fromondus, 3 October 1637; CSMK, pp. 62-3; AT I, p. 414)); see $\S 4.3$ for an analysis of such claims. 
and again that the human body is properly to be described as a machine whose workings are $[\ldots]$ driven by the heat in the heart that is the principle of life" (2003b, p. 240; my emphasis). In Le Principe de vie chez Descartes, Bitbol-Hespériès writes " $[t]$ he principle of life $[\ldots]$ is conceived of as the logical initial term, or the fundamental proposition, that accounts for the phenomenon of life" $(1990$, p. 25). This reading of Descartes's principle of life as some kind of initial term, or foundation, for his physiology tends to be affirmed either tacitly or explicitly wherever the subject is brought up (e.g., Aucante 2006, p. 164; Des Chene 2001, pp. 3, 26; Fuchs 2001, p. 131; Gaukroger 2008, pp. 10-11; Shapiro 2011, pp. 272-3, 282; Smith 2007, p. 624).

This paper challenges that reading of the principle of life. It argues for a distinction between (1) the general claims that Descartes appears to make about the principle of life and (2) the role this ostensible principle has in his physiology. My position is that, when it comes to (2), there is no single underlying principle. In spite of (1), Descartes's account of physiology takes the body to be structured in such a way that it can have no such principle - that is, interdependently rather than hierarchically. The body itself is structured interdependently in that the major bodily systems are dependent on each other, and not on an underlying principle that "drives" them. At the same time, there can be no single underlying principle even epistemologically: Descartes's account of the living body is structured interdependently too, in that knowledge about physiology depends on knowledge about all the major systems and their interactions, rather than being built up on top of some primary "initial term." This means that neither life functions themselves nor our knowledge of them is reducible to a single principle.

My position is that, for Descartes, cardiac heat depends on (at least) circulation, respiration, and digestion (see $\$ 4.1$ ), all of which themselves reciprocally depend both on cardiac heat and on each other. Brown (2011, pp. 11-13) has previously identified interdependence in Descartes's account of generation (embryogenesis), where " $[\mathrm{t}] \mathrm{he}$ process by which one organ is formed and operates is not independent of the processes by which others form and operate and this whole matrix of interdependent processes continues until a relatively closed system [...] comes into being" (12). ${ }^{3}$ Here, I show that interdependence is an ongoing state of the living body for Descartes, and that we can use this to make sense of what would otherwise look like his rather bizarre treatment of the ostensible principle of life $(\S 5)$.

2. "Le principe de vie $[\ldots]$ est conçu comme terme rationnellement premier, ou proposition fondamentale rendant compte du phénomène vital."

3. See $\$ 4.2$ for further discussion of Brown 2011. 
My intention here is not to accuse Descartes of inconsistency. Rather, the paper's aim is to tease out the consequences of Descartes's physiology in order to show that what is going on there is somewhat different from, and perhaps more interesting than, what he appears to claim to be doing. ${ }^{4}$ I begin by setting out the reasons for thinking that cardiac heat might indeed be the "initial term" of the physiology, or the engine that "drives" it (\$2). I then set out Descartes's account(s) of cardiac heat ( $\$ 3)$, before giving a constructive reading of his physiology, in which the major bodily functions are shown to be interdependent (§4). Finally, I show how the interdependence reading makes better sense of Descartes's treatment of cardiac heat $(\S 5)$, and how it obviates the need for any unitary fundamental principle (§6).

\section{Principles}

When Descartes uses the phrase "principle of life," there are two obvious connotations: (1) "principle of life" is a standard designation of the soul in the Aristotelian tradition (see $\$ 2.1)$; (2) principles are foundations in Descartes's famously foundational system of knowledge (see §2.2). Since the soul is the source of life for Aristotle, the natural conclusion to draw from (1) is that Descartes's principle is supposed to be the ontic ${ }^{5}$ foundation of physiology on his account of the body - that is, the principle of life is what drives the body itself. Similarly, it seems natural to suspect that, given (2), along with certain passages that appear to claim as much, the principle of life is meant to be the epistemic foundation for Descartes's sciences of physiology and medicine.

In the following three subsections, I set out what it would mean for Descartes to have a principle of life in senses (1) and (2), along with reasons for thinking that his principle of life might indeed be the ontic and epistemic foundation of his physiology. I take it that these are misleading ways to think about what Descartes calls the "principle of life"; they need to be clarified first, in order to show, second, precisely how they mislead.

4. Whether or not he is fully aware of the interdependence in his physiology, and its implications for his principle of life, is not entirely clear. His readiness to appeal to a principle of life would suggest not, but see $\$ 4.3$ for some evidence to the contrary.

5. I am not thinking, of course, of the fundamental ontology of extended and thinking substances here, but of "ontic" in the sense used in more recent philosophy of science (e.g., Machamer et al. 2000). In this case, the "ontic" is concerned with the body itself and what it contains, as opposed to knowledge thereof. We might instead want to think of the ontic principle as the motive principle of the body, but this would obscure the distinction between the principle of the body itself and the principle of our knowledge of the body; it would also exclude the ontic principle from being something more than just the source of motion in the body (see $\S 4.2$ ). 


\subsection{The Case for an Ontic Foundation of Physiology}

When Descartes brings up his principle of life, it is almost always in express contrast to a position of the "ancients" or of the "schoolmen" - that life is attributable to the soul. The position he counters takes the soul to be the source of life, and the engine that drives the self-movement of the living body. This makes the soul the ontic foundation of the living body insofar as it makes all life functions ultimately dependent on the soul. On this account, the dependency relations for life are hierarchical and go oneway only: the operations of the living body depend on the soul, while the soul is independent of the operations of the living body.

As Des Chene notes, "[i]n Aristotelian natural philosophy [...], the soul $[\ldots]$ is the principle of life. For [pre-eminent scholastic] Suárez, this is even a matter of definition" (Des Chene 2001, p. 30). Descartes, however, wholly rejects this function for the soul. He repeatedly assures us that life-conferring souls are an unnecessary supposition, because the material body by itself is sufficient for life (e.g., AT xI, p. 202; AT vi, p. 46; AT xI, p. 330; AT I, pp. 413-14). Particularly telling is a letter to Regius, where Descartes writes, "it goes against logic to conceive the soul as a genus whose species are the mind, the vegetative power and the locomotive power of animals" (May 1641; CSMK, p. 182; AT III, p. 371). This is because his ontology gives him a far more restrictive definition of the soul than was available to Aristotelians, since it allows for only two substances: matter and mind. The mind is identical with the soul for Descartes (and is entirely distinct from matter). On this definition, it is mind that is the genus, making the soul nothing but thought. Consequently, the soul cannot take on any life-founding role precisely because life-founding is a not species of thought. Taking the task of animating the body away from the soul allows Descartes to attribute life to animals as much as to humans while still maintaining that it is only humans that get souls. ${ }^{6}$

In the context in which Descartes took himself to be, where life required a soul as the driving force of the body, it would make sense for a physiology that explicitly excludes the psychic to provide its own substitute for the life-conferring soul. Indeed, this appears to be precisely how Descartes employs the term "principle of life" - in the Aristotelian sense, but with the psychic element swapped for something more Cartesian (despite his protestations about "departing from the paths" of the "ancients" (CSM I, p. 328; AT XI, pp. 327-8)). As T. S. Hall argues, "the explanations [Descartes] developed were corpuscularized, nonpsychistic versions of psychistic explanations

6. For an animal to have a soul "is unlikely, because there is no reason to believe it of some animals without believing it of all, and many of them such as oysters and sponges are too imperfect for this to be credible" (to Newcastle, 23 November 1646; CSMK, p. 304; AT Iv, p. 576). 
put forth earlier by others" $(1970$, p. 63$) .^{7}$ On this reading, the Aristotelian principle of life would be imported (along with the ontic connotation that there is a principle of life that drives the body) and simply reinterpreted in as a process compatible with Descartes's ontology.

For the Aristotelians, only certain bodies could be alive: bodies with organs, in the right arrangement. The body consists of an organization of matter independent of the soul; what the soul does is confer life by actualizing the potential of that material organization. ${ }^{8}$ The basic structure of this understanding of life was not restricted to the Aristotelian position that Descartes explicitly opposed either. Contemporary Paracelsian medical theory attributed archei to every organ. Each archeus controls its own organ and is (semi-)independent, with some degree of interaction between different organs. ${ }^{9}$ This interaction is also a form of organization within the body. But all these subarchei are ultimately answerable to a "master" archeus, an "internal president, curator and rector" (Van Helmont, quoted in Pagel 1982, p. 98). ${ }^{10}$ On Descartes's account, the organization of the organs remains, while the Aristotelian soul and the Paracelsian master archeus are both absent. The question is whether he replaces them with a Cartesian principle that fulfills the same role.

If he is to replace them, and if the soul is off-limits, then there is only one other option for a principle of life in Descartes's dualistic ontology: it must reside in matter. Descartes is committed to a material world that operates mechanistically - through nothing more than the "shape, size, position and motion of particles of matter" (CSM I, p. 279; AT viIIa, p. 314). And he explicitly describes the living body as a machine (AT vI, p. 56; AT XI, p. 120; AT XI, p. 226). As such, an ontic principle of life would be the mechanism that drives that machine. This is precisely what appears to be at stake when Descartes compares the body to a watch in his Treatise on the Passions of the Soul:

the difference between the body of a living man and that of a dead man is just like the difference between, on the one hand, a watch or other automaton (that is, a self-moving machine) when it is wound

7. See also Bitbol-Hespériès 1990; Hatfield 1992, p. 341; Des Chene 2001, p. 29; Aucante 2006, pp. 166-79, and Joly 2011, p. 123; more generally, Rozemond 1998; Ariew 1999. But cf. Lindeboom 1979, p. 69: "the feu sans lumière has nothing to do with the vegetative or the sensitive soul," but "[i]n the chaleur of the heart which heats the blood, the old Aristotelian innate heat (calor innatus) is easily recognized"; if it's not one thing, it's another.

8. See Des Chene 2000, pp. 81ff., 112.

9. See Clericuzio 2012, p. 331.

10. I am grateful to an anonymous reviewer for pointing out the relevance of the Paracelsian position here. 
up and contains in itself the corporeal principle of the movements for which it is designed, together with everything else required for its operation; and, on the other hand, the same watch or machine when it is broken and the principle of its movement ceases to be active (Passions 1/6; CSM I, pp. 329-30; AT XI, pp. 330-31).

The analogy seems clear: just as a watch has a principle of movement, a living body has a principle of life; the latter is to the body as the mainspring is to a watch. ${ }^{11}$ The passage also makes evident that Descartes equates life with self-movement here (as he also does elsewhere, such as in his letter to Regius of June 1642 [AT III, p. 566], since the analogue of the dead body is the watch with the inactive principle of motion. Given that it is self-movement in which Descartes is interested, the ontic principle of life would be the "spring" mechanism that drives the movements of the machine that is the living body. ${ }^{12}$

\subsection{The Case for an Epistemic Foundation of Physiology}

If there is such a thing as the Cartesian principle of life, it seems likely that it is meant to be the ontic motive force within the body. But the significance of principles in Descartes's epistemology is hard to ignore, and there is a certain amount of textual evidence to suggest that Descartes wanted a foundational principle for his physiology. After all, physiology is concerned with living things, and an epistemic principle of life would ground knowledge precisely of living things. ${ }^{13}$ Moreover, it is both easy and natural to take Descartes's physiology to be a hierarchical science, with all the knowledge it includes having been built on top of a solid foundation. This is presumably what Bitbol-Hespériès has in mind when she refers to the principle as the fundamental proposition that accounts for life (1990, p. 25).

11. Note, however, that the analogy refers to more than just the principle-there is also "everything else required for its operation." In $\$ 4$, I argue that there is good reason to privilege the "everything else" over the principle. See especially $\S 4.3$ for an alternative analysis of Descartes's claims about the principle of life.

12. Even if the ontic principle of life were the body's motive principle, it would be a mistake to take self-movement to be a generalized concept of life for Descartes, since that would not exclude manmade automata (such as watches). On the thorny issue of Descartes's general concept of life, see MacKenzie 1975; Ablondi 1998; Detlefsen 2016, and Hutchins (this ms. 2016).

13. Detlefsen argues that if Descartes had "no way of isolating a class of bodies taken to be living bodies, $[\ldots]$ he would then not be able to identify any individuals to serve as the subject matter of the life sciences - sciences to which he devoted considerable professional time. And this would render incoherent this aspect of his life as a working natural philosopher" (2016, p. 142). 
As Descartes claims in the famous letter-preface to the French edition of the Principles of Philosophy,

the whole of philosophy is like a tree. The roots are metaphysics, the trunk is physics, and the branches emerging from the trunk are all the other sciences, which may be reduced to three principle ones, namely medicine, mechanics, and morals (CSM I, p. 186; AT Ixb, p. 14).

The clear implication is that medicine (by which we should also understand physiology ${ }^{14}$ is a hierarchically high-level outgrowth of physics. From the simile, we might expect knowledge of medicine and physiology to be constructed on top of a foundation in physics, just as a branch grows progressively out of a certain point on the trunk.

A few pages earlier in that same preface, Descartes tells us that, in order to do philosophy, we have to begin by looking for basic principles (AT Ixb, p. 2). Since this is a preface to a textbook intended to encompass the whole of the tree of knowledge, "philosophy" here is unquestionably meant to involve medicine as much as metaphysics. ${ }^{15}$ The basic principles form the foundations on which knowledge can be built:

the knowledge of other things must depend on [these principles], in the sense that the principles must be capable of being known without knowledge of these other matters, but not vice versa (CSM I, pp. 180-81; AT Ixb, p. 2).

That is, on the hierarchical account, epistemic dependency relations work one-way only. As such, the dependencies reflect the hierarchy: hierarchically higher-level knowledge depends on foundational principles, and emphatically not vice versa.

Given nothing more than Descartes's general statements about his own epistemic methodology, then, it would make a certain amount of sense to think that something along the following lines is what is going on in Descartes's investigation of physiology. First, it seems as though Descartes should be looking for an epistemically foundational principle. ${ }^{16}$ This principle should be taken from his physics, and its purpose would be to bring living bodies within the epistemological grasp of his philosophical

14. See $\$ 2.3$, this ms. on Descartes's conception of the relation between physiology and medicine, and Aucante 2006.

15. See Aucante 2006 and Manning's 2007 extended review for thorough and convincing analysis of the position of physiology and medicine within Descartes's philosophy.

16. This would be a principle in the second sense discussed by Clarke: "[o]ne sense of 'principle' refers to propositions which are guaranteed as certain; the other meaning of the term applies to things the knowledge of which is basic for understanding anything else" (1982, pp. 80-81). 
system. Once he had such a principle, he could presumably then construct his account of physiology hierarchically, beginning with basic, low-level bodily functions, and then intermediate functions, and then higher functions (presumably, e.g., sensation). These are the presuppositions of an epistemically hierarchical account of physiology, in which knowledge of the living body always reduces to an epistemic foundation. ${ }^{17}$ By Descartes' own claimed standards, all this ought to give him good, firm knowledge of the animal/human body. This may well be what he had in mind when he wrote to Mersenne, "[p]lease look after yourself, at least until I know whether it is possible to discover a system of medicine which is founded on infallible demonstrations, which is what I am investigating at present" (January 1630; CSMK, p. 17; AT I, p. 105).

With a hierarchical account of this kind, perhaps it would even make sense for Descartes's explanations of some of the hierarchically higher bodily functions to be somewhat obscure (as indeed they are on occasion), since we could at least be sure that he had the basics right, given that the explanations were derived from a solid foundation. Accordingly, we could expect Descartes's physiology to comprise firm, strong, clear accounts of the more fundamental bodily systems, along with somewhat more flimsy, more obscure descriptions of the higher functions. Crucially, on this reading, we should expect the firmest account to be reserved for the underlying principle-after all, it is the underlying principle that is supposed to confer reliability to the knowledge of physiology (and medicine) that is supposed to be derived from it.

\subsection{Descartes's Principle of Life as a Foundation}

We have established that, in order to be an ontic foundation, the principle of life would have to be the "engine" that drives the body and confers life to it (so as to fulfill the ontic function of the Aristotelian psychic principle of life), as well as being mechanical and material (so as to Cartesianize the principle). In addition, in order to be an epistemic foundation for physiology, Descartes's principle of life would have to be an account derived from (or reducible to) his physics that is sufficiently firm to ground the knowledge of the entire science of physiology. ${ }^{18}$ In Descartes's case, the account

17. Methodologically, Descartes constructs his physiology through various means: experiments, anatomical observation, incorporation (and modification) of existing explanations, and, arguably, speculation. If his physiology were epistemically hierarchical, underpinned by an epistemically foundational principle, reducibility to that principle would be the arbiter of which explanations obtained by those means are admissible into the science.

18. There has been a significant amount of work in recent years on elements of Descartes's physiology and medicine that do not seem to be derived from, or even to be compatible with, 
would be sufficiently firm only if it is fully-reducible to the ultimate foundation of his physics, i.e., extension. This requires explanation in terms of corpuscular mechanics - the shape, size, and motion of subvisible particles.

On the face of things, Descartes's references to his principle of life would appear to fulfill all these criteria perfectly. What such a reading picks up on, however, is Descartes's general claims about the principle of life. It is at this point that it is helpful to distinguish between Descartes's general claims and his actual treatment of the "principle" within his physiology, because the former tends to obscure the latter. My contention here is that while Descartes's general claims do (at least) appear to present cardiac heat as the epistemic and ontic foundation of physiology, his actual account of physiology does away with any unitary foundation. In this section, I disambiguate the general claims before moving on, in the next, to an analysis of the role that cardiac heat plays in Descartes's account of the body.

When Descartes talks about a principle of life, it is fairly unambiguous that what he has in mind is cardiac heat-or, in a memorable turn of phrase, the "fire without light" in the heart (AT VI, p. 46). He sometimes invokes the blood as the principle as well, and, once, the whole body (see $\S 4.3$ ), but the scholarship tends to see these references as ultimately reducing back to cardiac heat. ${ }^{19}$ In the Treatise on Man, Descartes tells us that,

it is not necessary to conceive of this machine [the body] as having any $[\ldots]$ other principle of movement and life, apart from its blood and its spirits, which are agitated by the heat of the fire burning continuously in its heart (CSM I, p. 108; AT XI, p. 202).

Descartes's implicit target here is the Aristotelian conception of life. ${ }^{20}$ Vital souls are precisely what Descartes is referring to when he talks about additional principles of life over and above the physical mechanisms of the

his physics. These are mostly issues of apparent teleology; see, e.g., Gaukroger 2002 on extrinsic purposes; Des Chene 2001 on the notions of "function" and "office"; Des Chene 2002 and Shapiro 2003a on health; Brown 2011 on function; and Distelzweig 2015 on usus and function. Given that Descartes makes no claim to task these notions with grounding physiology, they might perhaps come under the remit of the "acceptably obscure" as discussed in $\S 2.1$, this ms. above.

19. Bitbol-Hespériès 1990 , ch. 3 gives a thorough overview of cardiac heat as the principle of life. See also, e.g., Aucante 2006, p. 164; Des Chene 2001, pp. 3, 26; Fuchs 2001, p. 131; Gaukroger 2008, pp. 10-11; Shapiro 2003b, pp. 240; 2011, pp. 272-3, 282, and Smith 2007, p. 624 for evidence of the consensus that cardiac heat is the principle of life.

20. Descartes's correspondence with Plempius makes the implicit target entirely explicit: "how, I ask, can the movement which occurs in the cut-up bits of the heart depend on the human soul, when it is taken as an article of faith that the rational soul is indivisible, and has no 
body (Descartes's "spirits" here are explicitly material ${ }^{21}$ ); his point is that we can find everything we need to account for life in the material of the body, and the supposition of a life-conferring soul on top would be a redundant step. From the way he puts it here, it sounds as though everything particular to a living body-its "movement and life"- has a single underlying principle: blood and spirits agitated by the fire in the heart. And since the agitation of the blood and spirits is itself dependent on the heat of the fire, it seems only natural to simplify the principle further, to the heat in the heart itself. ${ }^{22}$

Descartes is fairly consistent with this description in his general claims about the principle of life. The Treatise on the Passions of the Soul, a much later text, begins with a summary of his physiology. Its seventh article is titled "A brief account of the parts of the body and of some of their functions" (1/7; CSM I, p. 330; AT XI, p. 331), which covers the main functions of living bodies, from digestion to circulation to sensation. The next article addresses "The principle underlying all these functions." And that principle, it seems to claim, is cardiac heat:

[w]hile we are alive there is a continual heat in our hearts, which is a kind of fire that the blood of the veins maintains there. This fire is the corporeal principle underlying all the movements of our limbs (Passions 1/8; CSM I, p. 331; AT xI, p. 333).

Even more explicitly than the Treatise on Man, the Passions indicates that there is a principle that acts as the ontic foundation of the body, and that this principle is cardiac heat. From what Descartes claims here, cardiac heat underlies "all the movements of our limbs." As such, it drives the body - as Des Chene nicely puts it, "[i]n the cycle of the blood, the motor is the heat of the heart" (2001, p. 21). Descartes describes cardiac heat as "corporeal" (and thereby material, and by implication mechanical), and thus non-psychic. On the strength of such general claims about the principle of life, then, it appears that it does indeed serve as an ontic foundation for physiology.

The epistemic side of the ostensible principle comes out in the Description of the Human Body (a late text that recapitulates and updates much of the Treatise on Man). The preface explicitly puts the Description into an

other sensitive or vegetative soul attached to it?" (15 February 1638; CSMK, pp. 80-81; AT i, p. 523). See also Des Chene 2001, pp. $15 \mathrm{ff}$.

21. In Man, he calls them "a certain very fine wind," produced from the finest particles of the blood (CSM I, p. 100; AT XI, pp. 129-30). As Voss puts it neatly in a note on his translation of the Passions, "more spiritous than spiritual" (Descartes 1989, p. 24).

22. See Bitbol-Hespériès (1990, p. 38). 
epistemological setting. It begins by discussing the importance of medical knowledge, in terms of curing and preventing illness, and for the sake of retarding the aging process. Descartes then asserts the dependence of medical knowledge on physiological knowledge. Medicine could have obtained better clinical results, he claims, "if we had studied sufficiently to know the nature of our body" (DHB, p. 170; AT xI, pp. 223-24; translation modified $\left.{ }^{23}\right)$. He continues by explaining that the chief impediment to medical knowledge has been the erroneous attribution of life functions to the soul. This is immediately followed by a claim similar to those we have already seen in Man and the Passions, that cardiac heat is the ontic principle driving the living body (AT xI, p. 226). After a detailed account of the heartbeat, circulation, respiration, and nutrition, Descartes provides an explicit statement of the move from the ontic to the epistemic:

it is so important to know the true cause of the heart's movement that, without it, we cannot know anything about the theory of medicine, because all the other functions in the animal depend on it (DHB, p. 182; AT xI, p. 245).

He seems quite unequivocal that all knowledge of medicine and physiology is dependent on knowledge of "the true cause of the heart's movement" - in other words, given the preceding account, on knowledge of cardiac heat. This certainly sounds like an epistemic foundation for physiology. The passage also tells us something about the relation between the ontic and epistemic sides of the principle: we cannot know anything about medicine and physiology without knowledge of cardiac heat, Descartes claims, because the ontic constitution of the body is such that all its functions are dependent on cardiac heat as the ontic principle that drives them.

\section{Accounts of Cardiac Heat}

\subsection{The Source of Cardiac Heat}

Since cardiac heat is so widely identified with Descartes's principle of life (and for good reason), we need to determine exactly what is involved in Descartes's account before assessing whether it can serve as a principle. Merely referencing cardiac heat is not in itself going to be sufficient to make it the Cartesian principle of life. Cardiac heat is already present in relation to the principle of life in the theories of the "ancients" to whom

23. The original French reads, "si on s'estoit assez étudié à connoistre la nature de nostre corps" (AT xI, p. 224). 
Descartes so strenuously insists he is opposed. ${ }^{24}$ If Descartes is to distinguish his physiology from that of the ancients, he will have to provide an account of the source of cardiac heat that differentiates itself from the psychic account by being reducible to corpuscular mechanics, and ultimately to pure extension itself.

At this point, it might be objected that, as Des Chene (2001, p. 27) notes, heat is already mechanical for Descartes, given his account of heat as corpuscle movement in the World and the Principles. If heat itself is mechanical, then, by extension, cardiac heat should also be mechanical. ${ }^{25}$ If this is the case, does pointing to heat alone get to count as a mechanical explanation? No, because heat itself is not what is at stake here. While Descartes has provided a material explanation of heat elsewhere, his explanation of cardiac heat cannot bottom out in heat itself. There is another level to the causal story-namely, the cardiac part. The nature of heat itself is not the relevant question here. What is relevant is what causes heat specifically in the heart.

\subsection{Analogies}

In all of Descartes's completed work on physiology and medicine, he accounts for the heat of the heart purely through various allusions and analogies. The most common of these is fire. Thus, respiration is offhandedly described as "necessary for maintaining the fire in [the] heart" (TM, p. 102; AT XI, p. 124), while, according to the Passions, "we die when the fire in our heart is completely extinguished" (2, p. 122; CSM I, pp. 370-71; AT XI, p. 418). The same general attribution of cardiac heat to some kind of fire comes up again in both Man (AT xI, p. 202) and the Passions (1, p. 8; 2, p. 123), as well as in the Description (AT XI, pp. 236, 237, 244, 280-82) and the correspondence (AT iv, p. 407).

In Man (AT XI, p. 123) and the summary thereof included in the Discourse, Descartes expands a little on the fire allusion. In the latter, he writes,

in the beginning God did not place in this body any $[\ldots]$ other thing to serve as a vegetative or sensitive soul, but rather [...] he kindled in its heart one of those fires without light (CSM I, p. 134; AT vI, p. 46).

The idea of a fire without light might sound odd in itself, but it makes sense in context. In the Treatise on Light, an earlier section of the World, intended to be published alongside Man, Descartes accounts for fire in terms of flame burning wood (AT x, pp. $7-10) .{ }^{26}$ There, fire is produced by

24. See Bitbol-Hespériès 1990, p. 39 and Aucante 2006, pp. 167-77.

25. See Hall 1970, p. 62.

26. The account is reprised in Principles 4/80. 
very fast-moving subvisible bodies breaking apart the particles that make up the wood. Descartes wants to equate the fire that produces heat in the heart with that which produces heat in the flame-simply without the light.

Descartes associates such fires without light with fermentation, and it is comparisons with fermentation that make up the rest of his analogies with the cause of cardiac heat. In the Discourse, he claims that the fire in the heart is "no different from that of the fire which heats hay when it has been stored before it is dry, or which causes new wine to seethe when it is left to ferment from the crushed grapes" (CSM I, p. 134; AT vI, p. 46). In the Description, the comparison is to yeast (levain) (AT XI, p. 228; AT XI, p. 282), and the correspondence with Plempius mentions both yeast (AT I, p. 523) and fermentation in general (AT I, p. 523, 531; AT II, p. 69). Descartes's reference to "the fire which heats hay when it has been stored before it is dry" is particularly relevant, since his account of fermentation, which is given in the Principles, addresses its topic solely through the self-heating of damp hay.

Article 92 of part four of the Principles is titled "In things that grow hot but do not shine [lucent], such as stored hay" (4/92; CSM I, p. 273; AT villa, p. 256) - the context here is the nature and generation of fire, introduced in article 80. The claim is that the movement of the sap within pieces of hay can cause heat. There are channels in a blade of grass through which the sap usually flows; under normal circumstances, it would evaporate through those channels as the grass dries. But, as a blade of grass dries, its parts constrict, and, under certain conditions, the channels will constrict enough to seal themselves before the sap can evaporate. When that happens, the sap is forced faster and faster through smaller and smaller, ever-shrinking channels. This movement agitates the matter around it, causing heat. This, Descartes tells us, is a form of fermentation, and all fermentations operate in the same basic fashion: relatively large particles of matter get forced to move faster than normal (AT viIIa, p. 256).

Descartes has a mechanical explanation of fermentation, then-at least in the case of drying hay. He also claims that cardiac heat is caused by a kind of fermentation (or that its cause is like fermentation). Nevertheless, it is still not at all clear how the hay model applies to the heat of the heart. On Descartes's account there is no hay in the heart-and not obviously anything like it - and there is nothing in the process of drying. The account of fermentation in damp hay seems to apply to a fairly narrow set of circumstances. This is a very different set of circumstances from those in the heart. As such, the comparison with hay is not, by itself, going to show anything more than a very weak similarity between the two processes. Translating the model to the heart would require further specification of how the mechanical causes of fermentation in hay are manifested in the heart. 


\subsection{Blood-Expulsion}

Further specification is not provided in the discussions of cardiac heat in Man, the Discourse, or the Passions; nor is it to be found in the extended treatment that makes up part two ("On the motion of the heart and the blood" (DHB, p. 172; AT XI, p. 228)) of the Description. It comes up instead, somewhat incongruously, in a section of the Description concerned with embryology. There, Descartes provides a brief but complete account of the cause of cardiac heat through blood expulsion:

I do not know of any other fire or any other heat in the heart other than the agitation of the particles of blood, nor of any other cause which can serve to maintain this fire except only that, when most of the blood leaves the heart at the time of diastole, those of its particles which remain there enter into the flesh, where they find pores arranged in such a way, and fibres agitated in such a way, that there is only matter of the first element surrounding them; and at systole these pores change shape because the heart lengthens, which makes the particles of blood, which remained there as if they were to serve as yeast, leave there with a great speed, and in this way entering easily into the new blood coming into the heart, they make its particles separate from one another, and in separating thus they acquire the form of fire (DHB, p. 203; AT XI, pp. 281-2).

This has fairly clear parallels with the account of fermentation in hay, although Descartes does not make them explicit. The blood that remains in the heart is the equivalent of the sap in the blade of grass. It sinks into pores in the flesh of the heart, which play the role of the channels in the grass. At systole (which is the passive phase of the heartbeat for Descartes), the heart relaxes into an elongated shape, ${ }^{27}$ which causes the pores to be laterally compressed. This compression of the pores stands in for the constriction of the channels in the drying hay, expelling the particles of blood from the flesh of the heart wall, and into the new blood that enters the heart concurrently. The agitation of the accelerated blood particles, in turn, agitates the particles of the new blood, making them move and thus producing heat. ${ }^{28}$ This causes the blood to expand, on the macro level, and the heart goes into diastole, and the whole process repeats.

This passage provides a translation of the account of fermentation in hay over to the production of cardiac heat. It does what the analogies Descartes

27. See Description 2/10 (AT XI, p. 231).

28. Fuchs describes this stage of the process as a "ceaseless chain reaction" (2001, p. 128), brought about by the ejection of the old blood (however, there is no indication of any chain reaction in Descartes's account). 
employs in his completed works, in his correspondence, and in the Description's own treatment of cardiac motion do not: it explicitly accounts for the generation of heat specifically in the heart.

\section{Interdependence and the Case against an Ontic Foundation}

\subsection{Interdependence and the Engine of the Body}

On the basis of Descartes's explanation of the cause of cardiac heat, we can assess whether the heat of the heart can be said to "drive" the body on his account of physiology (and thus whether it can serve as the ontic principle of the movement of the living body). On my reading, it will turn out that there can be no unitary principle driving the Cartesian body, just because the major systems of Descartes's physiology are interdependent rather than being organized hierarchically: no one system can be more fundamental than another.

When Descartes writes that we "move just like automatons, and nobody thinks that the force of heat is insufficient to cause their movements" (to Plempius for Fromondus, 3 October 1637; CSMK, p. 63; AT I, p. 414), he appears to be quite clear that it is heat that drives the body. If cardiac heat were the engine of the body, it would drive the body's movements just because it causes the blood to circulate and because it produces animal spirits. This is how he describes the operation of the body in the preface to the Description:

the heat that [the body] has in its heart is like the great spring or the principle of all its movements, and [...] the veins are the tubes which conduct the blood from all the parts of the body towards the heart, where it fuels the heat there] [...]. And the arteries are yet another set of tubes, through which the blood, heated and rarefied in the heart, passes from there into all the other parts of the body, to which it brings heat and matter to sustain them. Finally, the most agitated and most active parts of this blood are carried to the brain [...], comprising an air or very fine wind which is called the "animal spirits." These dilate the brain, enabling it to [...] [act] as the organ [...] of the common sense, of the imagination, and of the memory. Then, $[\ldots]$ these same spirits flow from the brain through the nerves into all the muscles, thereby making these nerves serve as organs of the external senses, and inflate the muscles in various ways imparting movement to all bodily parts (DHB, p. 172; AT xI, pp. 226-7).

Cardiac heat rarefies and heats the blood, which pushes it out through the arteries, whereby heat and nutrition is provided throughout the body. Cardiac heat also creates animal spirits, in the form of the smallest, most agitated particles of blood, which are released in the process of 
heating and rarefaction. The spirits, too, are pushed out of the heart by the rarefaction of the blood, and through the nervous system, whereby they power brain and sensation functions and "[impart] movement to all bodily parts."

On the basis of this description, the causal dependency relations within the body do appear to go one way: functions such as digestion and muscular movement depend on the circulatory and nervous systems respectively, which both depend on cardiac heat (and, ultimately, on the blood-expulsion that drives cardiac heat). On this account, cardiac heat gets to be the engine of the body because it sits at the bottom of the hierarchy: cardiac heat is the engine if that is where all dependencies in the body ultimately bottom out.

However, merely stating that such and such a thing is the principle behind something or other does not, in itself, make it that principle-at least, not for a Cartesian. ${ }^{29}$ The position needs to be substantiated. In the case of Descartes's principle of life, we need to establish whether it really does provide the motive power behind the movements of the body. (We also need to establish whether knowledge of the principle of life is used as the epistemic foundation of the science of physiology.)

For Descartes, heat itself is nothing but movement (AT XI, p. 10). For him to claim that what drives the movements of the body is heat, while what causes heat (in the body) is movement (in the body) would be akin to claiming that movement in the body is caused by movement in the body; that is, it would be circular. Heat in itself thus cannot serve as the ontic foundation of the body: we need the cause behind the heat. The bloodexpulsion account supplies that cause. Consequently, it is the bloodexpulsion account that we need to look at in order to establish whether cardiac heat can act as the engine that drives the body. To put it another way, cardiac heat has a further dependency: blood-expulsion. In order to see where, or indeed if, the dependencies in the body bottom out, we need to examine the dependencies for blood-expulsion.

According to the blood-expulsion account, cardiac heat is caused by the expulsion of particles of blood from the heart wall into cooler, non-rarefied blood that is simultaneously entering via "the vena cava into [the] right ventricle, and $[\ldots]$ the pulmonary vein into the left" (DHB, p. 174; AT xI, p. 231). This is what causes the heating and rarefaction of the blood that supposedly drives both circulation and animal-spirit production (and consequently the whole process of bodily functioning that Descartes describes

29. A non-Cartesian science might well be founded on an axiomatic principle that is not explained further. But any founding principle of Cartesian physiology would have to reduce all the way down to extension, the ultimate foundation of his natural philosophy. 
in the preface to the Description). But, on Descartes's account above, the production of cardiac heat through blood-expulsion depends on the following activities: (a) the addition of "fresh" blood to the ventricles and (b) the expulsion of blood particles from the heart wall. In order to have (a), the body needs both (a.1) blood and (a.2) a means of delivering it to the heart (i.e., circulation). And in order to have (b), the body needs both (b.1) blood in the heart wall and (b.2) a means of ejecting it at sufficient speed. Immediately, then, we see that blood-expulsion is dependent on something further. This means that the dependencies in the body cannot bottom out at blood-expulsion.

Following the dependencies for (b), we see that (b.2) depends on heartlengthening. The pores of the heart wall "change shape because the heart lengthens," and this is what "makes the particles of blood $[\ldots]$ leave there with a great speed" (DHB, p. 203; AT XI, pp. 281-2). Heart-lengthening itself is caused by the deflation of the heart following the active phase of the heartbeat (AT XI, p. 232). So, blood-expulsion is partially dependent on (b), which is partially dependent on (b.2), which depends on heart-lengthening, while heart-lengthening is caused by heart-deflation, which itself is an effect of heart-inflation. And heart-inflation is dependent on blood-expulsion. Any given activity in the process-blood-expulsion, heart-lengthening, heartdeflation, etc.-is dependent on the other activities in the process. That is, the entire process is circular, and the activities within it are interdependent. Similarly, a small amount of blood remains in the heart wall (b.1) only as a result of the previous active phase of the heartbeat (AT xI, p. 231), while the active phase is itself partially dependent on (b.1).

The dependency story plays out in the same way with (a). The addition of fresh blood to the ventricles partially requires the whole circulatory system (a.2) to bring the blood that was previously sent out from the heart back into it. At its simplest, we can say that, for Descartes, circulation depends on the heartbeat, which depends on the expansion of blood, which depends on cardiac heat, which depends on bloodexpulsion, which depends on circulation, and so on. Thus, circulation and cardiac heat are interdependent (along with blood-expulsion, heart-inflation and deflation, etc.). Descartes's account, however, is not quite so simple. The dependencies for cardiac heat bring in at least two more bodily functions: digestion and respiration. The addition of fresh blood via the circulation requires a supply of blood (a.1), which depends on the production of blood within the body. On Descartes's account, the production of blood depends on digestion (AT XI, pp. 122, 227). But digestion depends on the circulation of warm blood to provide it with the movement and material it requires to operate (AT XI, p. 121). Without circulation and cardiac heat, there would be no digestion-but without digestion, there would be no 
circulation or cardiac heat. As such, digestion, circulation, and cardiac heat are all interdependent. ${ }^{30}$

In addition, in order to derive the fresh blood that re-enters the heart from the re-circulating blood in the veins, Descartes's physiology requires respiration:

by means of the respiratory air, [the lung] thickens and tempers the blood that comes from the right ventricle of the heart before it enters the left ventricle; without this it would be too rare and too fine to serve to fuel the fire that it encounters there [my emphasis] (DHB, p. 177; AT XI, p. 236).

If there were no respiration, there would be no production of cardiac heat. ${ }^{31}$ Consequently, cardiac heat depends on respiration. At the same time, there would be no respiration without the flow of blood to the lungs, and without the movement with which the warm blood supplies them. Thus, respiration, circulation, cardiac heat, and digestion are all interdependent. Each depends on the others, and the absence of any particular one would prevent the operation of each and all the others.

Given this interdependence of bodily functions, a reading of Descartes's physiology in which cardiac heat is the underlying ontic principle of the living body - the engine that drives it-becomes untenable. At no point in the cycle is there reason to stop and name that particular stage the "engine." There is no single originator of movement in the body. There is no physiological first mover. There is nothing that fulfills the same role as the Aristotelian soul. There could be no cardiac heat without bloodexpulsion, and there could be no blood-expulsion without fresh blood entering the heart and without the discharge of blood particles from the ventricle wall. But blood-particle discharge requires heart-lengthening, which requires heart-deflation, which requires heart-inflation, and so on. None of which could occur anyway without the supply of blood that is dependent on digestion, or without the interposition of respiration.

There is no one point at which the dependencies bottom out. Instead, they continue in a perpetual circle throughout all of these bodily functions.

30. In the Description (AT xI, p. 239), Descartes mentions that the circulation would be a process of perpetual motion, if it were not for the loss of blood particles through nutrition. In a body without nutrition, there would be no need for digestion. In that case, digestion itself would not be one of the interdependent systems. Regardless, the body Descartes is describing is one in which there is nutrition, for which it is clear that, without digestion, cardiac heat, circulation, and respiration would fail, and digestion therefore belongs among the interdependent functions. On the connection between interdependence and systematicity in Descartes's physiology, see Hutchins 2015, pp. 675-8.

31. The same point is made in Discourse 5 (AT vI, p. 53). 
The circularity in Descartes's treatment of cardiac heat (movement caused by heat, but heat caused by movement) is thus virtuous rather than vicious, but only as a result of the interdependence of the functions involved. Descartes's physiology, therefore, cannot be hierarchical and ultimately driven by a single underlying principle. If there is an engine that drives the Cartesian body, it cannot be a single function; it must rather be the collection of interdependent functions as a whole that drives the body. The answer to the question raised in $\$ 2.1$ - whether Descartes replaces the Aristotelian soul (or the Paracelsian master archeus) with a principle of life compatible with his ontology - is thus a "no." He retains the organization of the parts of the body, and he makes that organization do all the work. He does away with the underlying principle entirely.

\subsection{Interdependence and Generation}

A potential objection to the argument here is that there is another sense in which cardiac heat might be conceived of as the underlying principle of life- not as the engine that continuously drives the body, but as the body's developmental point of origin. In Descartes's account of generation in the Description, the heart is the first organ in the embryo to begin to develop (AT XI, p. 254). Given that the heart develops via the heat generated by fermentation of the "mixture of seed" (DHB, p. 187; AT XI, p. 254), and that Descartes claims that "this movement of the diastole has from the beginning been caused by heat, or the action of fire [in this case, the "fire" of the fermenting seed from which the heart develops]" (DHB, p. 202; AT XI, pp. 280-81), there is a fairly clear argument for seeing the warm heart as the first principle, or the initial term, of life in the body.

However, even here, in the earliest generation of the heart, the dependency relations do not go one way only. Brown shows how the development of the embryo, on Descartes's account, requires the interdependence of the processes involved: "the formation of the brain is necessary for the persistence of the heart and the formation of the heart a necessary precondition for the formation of the brain" (Brown 2011, p. 86). Because the processes of generation form a virtuous circle of interdependence, exactly as do the bodily systems that maintain the ongoing operation of the body, the warm heart developing in the embryo has to share first position in the body with the other interdependent processes of generation. Consequently, there can be no single underlying principle of life in the generation of the Cartesian body either.

\subsection{Interdependence and Descartes's General Claims}

Even in his general claims, Descartes does not always refer to a unitary principle. When he brings up the "principle of movement and life" in 
Man, he first equates them with the man-machine's "blood and its spirits," before going on to tell us that the blood and spirits are "agitated by the heat of the fire burning continuously in its heart" (CSM I, p. 108; AT XI, p. 202). Similarly, in a letter to Plempius for Fromondus, he claims that "the souls of animals are nothing but their blood, the blood which is turned into spirits by the warmth of the heart" (3 October 1637; CSMK, pp. 62-3; AT I, p. 414). What is invoked in both these passages is something more than just cardiac heat, although it could certainly be argued that Descartes sees the principle underlying the blood and spirits here to be the heat of the heart.

There are other passages, however, that suggest Descartes might have been aware that his physiology actually operates on the basis of interdependence. In a letter to Plempius, Descartes attributes the rarefaction of blood in the heart to "[t] $\mathrm{t}$ he entire structure $[$ fabrica $]$ of the heart, the heat in it, and the very nature of the blood," all of which "contribute [conspirant] to this effect" (15 February 1638; CSMK, p. 83; AT I, p. 529; translation modified). As discussed in $\S 3$, it is the rarefaction of the blood that causes its expulsion from the heart. It is also blood rarefaction that creates the spirits. And, here, Descartes is explicit that its dependencies do not bottom out in cardiac heat, but that it is the product of several conspiring factors, with none being more fundamental than any other.

Even more tellingly, in a letter to Regius Descartes writes,

[ $t$ ] he vegetative power in human beings is nothing but a certain arrangement [constitutio] of the parts of the body (to Regius, May 1641; CSMK, p. 182; AT III, p. 372).

He sees the engine of the body not as a single underlying principle, but as a collection of parts in a certain arrangement. The analysis in this paper would suggest that we think of this arrangement of parts as the circle of interdependent functions. In a very similar vein, the Passions claims that

death never occurs through the absence of the soul, but only because one of the principal parts of the body decays [my emphasis] (Passions 1/6; CSM I, p. 329; AT xI, p. 330).

When the body dies, it is because of the breakdown of any one of some group of "principal parts." Descartes himself does not qualify which parts he takes to be principal, but, given the reading in $\S 4.1$, they must be those parts or functions that are interdependent. It is precisely the interdependent functions for which, if one ceases to operate, the whole body ceases to operate: death occurs if any of the principal parts decays exactly because each part is dependent on all the others. Descartes is quite clearly not placing the responsibility for life and death solely in the hands of cardiac heat: he 
explicitly does not offer cardiac heat alone as his alternative to the Aristotelian psychic principle of life. Instead, he places responsibility for the life of the body in the entire collection of principal parts.

\section{The Case against an Epistemic Foundation}

If physiology is structured interdependently rather than hierarchically, it can have no single underlying ontic principle. Given that Descartes's general claims make any epistemic principle of the science of physiology dependent on the ontic principle $(\$ 2.3)$, there is sufficient reason to conclude that his physiology has no single underlying epistemic principle either. But there is another case to be made against there being a single principle grounding the Cartesian sciences of physiology and medicine.

If cardiac heat were the principle on top of which knowledge of physiology is built, Descartes's treatment of it in his work on physiology would be remarkably strange. He deals with it offhandedly, devoting at least as much attention to the "auricles" of the heart, or to the proper designation of the pulmonary vein and artery, as to the generation of heat in the heart. There is a considerable difference between the amount of detail allotted to, say, the mechanism of nutrition and that afforded to the cause of cardiac heat. Recall (from §3.1) that, in all of his completed work, Descartes addresses the generation of cardiac heat solely through analogies and allusions. These analogies are vague and incomplete, and they get changed, mixed together, and recycled throughout Descartes's various works on the subject, in a way reminiscent of the interchangeable tropes of an elevator pitch ("the principle of life is like yeast meets damp hay").

If all that were at stake here were just some physiological phenomenon or another, the lack of specificity about the mechanism might well not matter epistemically. It would be what Des Chene calls a "proof of concept" (2001, p. 17): these kinds of things can happen in this kind of way. ${ }^{32}$ But knowing that fermenting wine effervesces or that drying hay heats up, in entirely different contexts, seems far too slight to serve as the foundational principle of a science for Descartes. These analogies do suggest that generation of heat and ebullition can be a material, nonpsychic process, but without further specification, they are insufficient for a foundational principle. As established in $\$ 2.2$, an epistemic foundation would have to comprise a well-specified account that reduces down to the principles of physics. The analogies alone do not fit that bill. What Descartes needs is a mechanical explanation of fermentation, and of how it (or something like it) occurs in the heart.

32. See also Hatfield 1992, p. 343 and Manning 2012. 
He does have such an explanation: the blood-expulsion account. But Descartes never uses that account to explain cardiac heat in any of his general physiology. The blood-expulsion account is given in the fifth part of the Description of the Human Body. The Description is an unfinished manuscript that Descartes worked on over the last couple of years of his life (it was composed between 1647 and 1648). It is divided into five separate parts: the first three cover the introduction, the heartbeat and circulation, and nutrition respectively, while the remaining two address embryogenesis and embryo development. In a 1648 letter to Elisabeth, Descartes describes embryology as being of the greatest necessity to his work, but complains that he lacks the relevant data (AT v, p. 112). The draft he finally produces is famously tenuous. In the 1664 edition (its first, and posthumous, publication), Descartes's editor Clerselier even sets the fourth and fifth parts of the Description aside, under the heading "Digression, in which the formation of the Animal is treated" (AT XI, p. 252). ${ }^{33}$ And it is in this context-and only in this context- that Descartes employs the bloodexpulsion account.

If this were meant to be the firm account that finally grounds Descartes's science of physiology, its relegation to a tentative treatment of embryology seems a strange choice. It makes no appearance in the first three parts of the Description, which are concerned precisely with the functioning of the body and the epistemic value thereof (see §2.1). When explaining the heartbeat, the Description employs only the vague allusions and analogies covered in \$3.2. In addition, since the blood-expulsion account was written in 1648 at the latest, there would have been ample time to insert it into the Passions' discussion of the principle of life and cardiac motion before publication at the end of $1649 .{ }^{34}$ But we find no mention of it there either; all the Passions tells us is that cardiac heat is caused by "a kind of fire" (CSM I, p. 331; AT xI, p. 333). If blood expulsion were the account that finally mechanized the very foundation of his physiology, we might well expect Descartes to be eager to include it in his newest work-a work that also happened to be the most thorough treatment of physiology he had yet to publish. ${ }^{35}$

If we take cardiac heat to be the grounding principle of Descartes's physiology, it is difficult to make sense of the remarkably laid-back approach he has to addressing the generation of heat in the heart. However, if cardiac heat is just one physiological phenomenon among many, and no

33. Adam and Tannery note that the heading appears to be due to Clerselier rather than to Descartes himself (AT XI, p. 252).

34. The Passions was officially published at the beginning of 1650 , but copies were available the preceding December.

35. Man remained unpublished until 1662 (in a Latin translation). 
more fundamental than circulation, respiration or nutrition, his treatment of it makes perfect sense. A proof-of-concept explanation is sufficient for one phenomenon among many. And a better specified explanation can reasonably remain buried in an obscure manuscript if nothing pivotal rests on the phenomenon in question.

The introduction to the Description might claim that we "cannot know anything about the theory of medicine" without knowing "the true cause of the heart's movement" (DHB, p. 182; AT xI, p. 245), but it is evidently a mistake to take that cause to be cardiac heat. We might still need to know the true cause of the heart's movement, but the cause is exactly what Descartes sets out in the sections of the Description that follow: the entire physiology of the interdependent "principal parts" of the body.

\section{Conclusion}

Descartes makes multiple references to a "principle of life," or to a principle that underlies the body's operations. This principle appears to be cardiac heat. There are some good reasons for taking these references to point to an ontic foundation of Cartesian physiology - where an ontic foundation is the "engine" that "drives" the body, or the point at which all the dependencies in the body bottom out. There are also good reasons to go further and interpret Descartes's "principle of life" as an epistemic foundation, on which all the knowledge of his physiology is grounded.

If, however, we look at the dependencies of cardiac heat, we see that it cannot be the ontic foundation of Cartesian physiology, because the Cartesian body is not driven by a single "engine" principle. Instead, the living body operates on the basis of a collection of interdependent bodily functions. These are (at least) cardiac heat, circulation, digestion, and respiration. In addition, cardiac heat cannot be the epistemic foundation of Cartesian physiology, since Descartes takes his epistemic foundation to depend on his ontic foundation. Thus, the structure of Cartesian physiology is not hierarchical, either ontically or epistemically, but interdependent. Precisely because it is structured interdependently, Cartesian physiology has no place for a single, underlying "principle of life."

\section{References}

\section{Works by Descartes}

(CSM I) Descartes, René. 1985. The Philosophical Writings of Descartes. Edited and translated by John Cottingham, Robert Stoothoff and Dugald Murdoch. Vol 1. Cambridge: Cambridge University Press.

Descartes, René. 1989. The Passions of the Soul. Translated by Stephen Voss. Indianapolis: Hackett. 
(CSMK) Descartes, René. 1991. The Philosophical Writings of Descartes: The Correspondence. Edited and translated by John Cottingham, Robert Stoothoff, Dugald Murdoch and Anthony Kenny. Cambridge: Cambridge University Press.

(AT) Descartes, René. 1996. Euvres de Descartes. Edited by C. Adam, P. Tannery. 11 vols. Paris: J Vrin.

(TM) Descartes, René. 1998. The Treatise on Man. Pp. 99-169 in Descartes: The World and Other Writings. Edited and translated by Stephen Gaukroger. Cambridge: Cambridge University Press.

(DHB) Descartes, René. 1998. The Description of the Human Body. Pp. 170205 in Descartes: The World and Other Writings. Edited and translated by Stephen Gaukroger. Cambridge: Cambridge University Press.

\section{Works by 0thers}

Ablondi, Fred. 1998. "Automata, Living and Non-Living: Descartes' Mechanical Biology and His Criteria for Life." Biology and Philosophy 13: 179-186.

Ariew, Roger. 1999. Descartes and the Last Scholastics. Ithaca: Cornell University Press.

Aucante, Vincent. 2006. La philosophie médicale de Descartes. Paris: Presses Universitaires de France.

Bitbol-Hespériès, Annie. 1990. Le principe de vie chez Descartes. Paris: J. Vrin.

Brown, Deborah. 2011. "Cartesian Functional Analysis." Australasian Journal of Philosophy 90 (1): 75-92. doi:10.1080/00048402.2011.566274.

Clarke, Desmond. 1982. Descartes' Philosophy of Science. Manchester: Manchester University Press.

Clericuzio, Antonio. 2012. "Chemical and Mechanical Theories of Digestion in Early Modern Medicine." Studies in History and Philosophy of Science Part C: Studies in History and Philosophy of Biological and Biomedical Sciences 43 (2): 329-337. doi:10.1016/j.shpsc.2011.10.025.

Des Chene, Dennis. 2000. Life's Form: Late Aristotelian Conceptions of the Soul. Ithaca, NY: Cornell University Press.

Des Chene, Dennis. 2001. Spirits E Clocks: Machine E Organism in Descartes. Ithaca, NY: Cornell University Press.

Des Chene, Dennis. 2002. "Life and Health in Cartesian Natural Philosophy." Pp. 723-735 in Descartes' Natural Philosophy. Edited by Stephen Gaukroger, John Schuster and John Sutton. London: Routledge.

Detlefsen, Karen. 2016. "Descartes on the Theory of Life and Methodology in the Life Sciences." Pp. 141-171 in Early Modern Medicine and Natural Philosophy. Edited by Peter Distelzweig, Benjamin Goldberg and Evan Ragland. Dordrecht: Springer. 
Distelzweig, Peter. 2015. "The Uses of Usus and the Function of Functio: Teleology and its Limits in Descartes' Physiology." Journal of the History of Philosophy 55 (3): 377-399.

Fuchs, Thomas. 2001. The Mechanization of the Heart: Harvey and Descartes. Translated by Marjorie Grene. Rochester, NY: University of Rochester Press.

Gaukroger, Stephen. 2002. "The Resources of a Mechanist Physiology and the Problem of Goal-Directed Processes." Pp. 383-400 in Descartes' Natural Philosophy. Edited by Stephen Gaukroger, John Schuster and John Sutton. London: Routledge.

Gaukroger, Stephen. 2008. "Life and Works." Pp. 3-16 in A Companion to Descartes. Edited by Janet Broughton and John Carriero. Oxford: Blackwell.

Hall, Thomas S. 1970. "Descartes' Physiological Method: Position, Principles, Examples." Journal of the History of Biology 3 (1): 53-79.

Hatfield, Gary. 1992. "Descartes' Physiology and Its Relation to His Psychology." Pp. 335-370 in The Cambridge Companion to Descartes. Edited by John Cottingham. Cambridge: Cambridge University Press. Hutchins, Barnaby R. 2016. "Descartes and the Dissolution of Life." The Southern Journal of Philosophy 54 (2): 155-173.

Hutchins, Barnaby R. 2015. "Descartes, Corpuscles and Reductionism: Mechanism and Systems in Descartes' Physiology." The Philosophical Quarterly 65 (261): 669-689.

Joly, Bernard. 2011. Descartes et la chimie. Paris: J. Vrin.

Lindeboom, Gerrit A. 1979. Descartes and Medicine. Amsterdam: Editions Rodopi.

Machamer, Peter, Lindley Darden and Carl Craver. 2000. "Thinking about Mechanisms." Philosophy of Science 67 (1): 1-25.

MacKenzie, Ann Wilbur. 1975. "A Word about Descartes' Mechanistic Conception of Life." Journal of the History of Biology 18 (1): 1-13.

Manning, Gideon. 2007. "Out on the Limb: The Place of Medicine in Descartes' Philosophy." Early Science and Medicine 12: 214-222.

Manning, Gideon. 2012. "Analogy and Falsification in Descartes' Physics." Studies in the History and Philosophy of Science Part A 43: 402-411. doi:10.1016/j.shpsa.2012.02.003.

Pagel, Walter. 1982. Joan Baptista Van Helmont: Reformer of Science and Medicine. Cambridge: Cambridge University Press.

Rozemond, Marleen. 1998. Descartes's Dualism. Cambridge, MA: Harvard University Press.

Shapiro, Lisa. 2003a. "The Health of the Body-Machine? Or Seventeenth Century Mechanism and the Concept Of Health." Perspectives on Science 11 (4): 421-442. 
Shapiro, Lisa. 2003b. "Descartes' Passions of the Soul and the Union of Mind and Body." Archiv für Geschichte der Philosophie 85 (3): 211-248.

Shapiro, Lisa. 2011. "Descartes's Pineal Gland Reconsidered." Midwest Studies in Philosophy 35: 259-286.

Smith, Justin E. H. 2007. "Vincent Aucante: La philosophie medicale de Descartes." Isis 98/3: 623-625. 